\title{
Blood velocities measured in the sinus coronarius by 3 T-MRI in patients operated for coarctation of the aorta Jochem Cuypers
}

\author{
Address: Department of Clinical Medicine, The University of Bergen, Bergen, Norway \\ from 13th Annual SCMR Scientific Sessions \\ Phoenix, AZ, USA. 21-24 January 2010 \\ Published: 21 January 2010 \\ Journal of Cardiovascular Magnetic Resonance 20 I0, I2(Suppl I):P3 I doi:|0.| I86/I532-429X-|2-SI-P3 I
}

This abstract is available from: http://jcmr-online.com/content/|2/SI/P3 I

(C) 2010 Cuypers et al; licensee BioMed Central Ltd.

\section{Introduction}

Coarctation of the aorta (CoA) counts for approximately $5 \%$ of the congenital heart defects. Most patients are operated during infancy. Late complications are rest- or recoarctation of the aorta, abnormal blood pressure response to exercise and hypertension at rest. Life-long follow up is therefore recommended. A number of papers report an increased risk of coronary heart disease in patients with congenital heart defects. Many factors may accelerate the arteriosclerotic process, but little is known about CoA as a risk factor. In addition to hypertension, an altered blood stream profile and flow reserve in the coronary arteries might be of importance.

\section{Purpose}

To uncover changes in the coronary circulation in patients with CoA by studying the blood velocities and blood flow reserve in coronary sinus.

\section{Methods}

This study was an open prospective study of 10 controls and 10 patients operated for CoA (15-25 years of age). The patients were recruited from our out-patient clinic. Patients with a bicuspid aortic valve were excluded from the study. Velocities were measured by the phase contrast velocity encoded cine magnetic resonance imaging technique (3.0 T GE Signa Excite scanner) in the sinus coronarius before and after infusion of adenosine $(0.14 \mathrm{mg} /$ $\mathrm{kg} / \mathrm{min}$ ). A special designed workstation based on java made it possible to select the region of interest and analyse the velocities. A 3D visualisation tool was used to quality ensure the location of the ROI.

\section{Results}

Preliminary data from five patients and five controls indicate a significant difference in the average velocity and flow between the CoA-group $(8 \mathrm{~cm} / \mathrm{s}$ and $14 \mathrm{ml} / \mathrm{s}$ ) and controls $(10 \mathrm{~cm} / \mathrm{s}$ and $8 \mathrm{ml} / \mathrm{s})$ at rest. A larger increase in average velocity and flow in the controls $(12,5 \mathrm{~cm} / \mathrm{s}$ and $14 \mathrm{ml} / \mathrm{s})$ than in CoA-group $(9 \mathrm{~cm} / \mathrm{s}$ and $16 \mathrm{ml} / \mathrm{s})$ was noted after infusion with adenosine. The coronary flow reserve (CFR) was calculated as 1.75 for the controls and 1.14 for the CoA-group. There are differences in the flow pattern between individuals within each cardiac cycle in both groups, more pronounced in the CoA-group.

\section{Conclusion}

At rest there is an elevated flow in the coronary sinus in patients operated for CoA. The CFR is reduced in patients operated for CoA, hence a smaller increase in the blood flow after infusion with adenosine compared with a control group. Additionally, individuals in the CoA-group have more heterogenous flow patterns. 